\title{
BMJ
}

\section{Relation between hospital orthopaedic specialisation and outcomes in patients aged 65 and older: retrospective analysis of US Medicare data}

\author{
Tyson P Hagen, rheumatology fellow, ${ }^{1,2}$ Mary S Vaughan-Sarrazin, research scientist, ${ }^{2,3}$ Peter Cram, associate \\ professor ${ }^{2,3}$
}

${ }^{1}$ Division of Rheumatology, Department of Internal Medicine, University of lowa Carver College of Medicine, lowa City, IA 52242, USA

${ }^{2}$ Center for Research in the Implementation of Innovative Strategies for Practice (CRIISP),

Iowa City Veterans Affairs Medical Center, lowa City

${ }^{3}$ Division of General Internal Medicine, Department of Internal Medicine, University of lowa Carver College of Medicine Correspondence to: T P Hagen tyson-hagen@uiowa.edu

Cite this as: BMJ 2010;340:c165 doi:10.1136/bmj.c165

\section{ABSTRACT}

Objective To explore the relation between hospital orthopaedic specialisation and postoperative outcomes after total hip or knee replacement surgery.

Design Retrospective analysis of US Medicare data, 2001-5. Setting 3818 US hospitals carrying out total joint replacement.

Population 1273081 Medicare beneficiaries age 65 and older who underwent primary or revision hip or knee replacement.

Main outcome measures Hospitals were stratified into fifths on the basis of their degree of orthopaedic specialisation (lowest fifth, least specialised; highest fifth, most specialised). The primary outcome was defined as a composite representing the occurrence of one or more of pulmonary embolism, deep vein thrombosis, haemorrhage, infection, myocardial infarction, or death within 90 days of the index surgery.

Results As hospital orthopaedic specialisation increased from the lowest fifth to highest fifth, the proportion of people admitted who were women or black, or who had diabetes or heart failure progressively decreased ( $\mathrm{P}<0.001)$, whereas procedural volume increased. Compared with the most specialised hospitals (highest fifth), after adjustment for patient characteristics and hospital volume, the odds of adverse outcomes increased progressively with decreased hospital specialisation: lowest fifth (odds ratio 1.59, 95\% confidence interval 1.53 to 1.65$)$, second fifth $(1.32,1.28$ to 1.36$)$, third fifth $(1.24,1.21$ to 1.28$)$, and fourth fifth $(1.10,1.07$ to 1.13$)$. Conclusions Increased hospital orthopaedic specialisation is associated with improved patient outcomes after adjusting for both patient characteristics and hospital procedural volume. These results should be interpreted with caution because the possibility that other unmeasured confounders related to socioeconomic status or different factors are responsible for the improved patient outcomes rather than hospital specialisation can not be excluded. The findings suggest that hospital specialisation may capture different components of hospital quality than the components captured by hospital volume.

\section{INTRODUCTION}

Hospital procedural volume is typically defined as the number of patients undergoing a specific procedure, such as bypass surgery, at a specific hospital over a circumscribed period. Since the 1980s numerous studies have found an association between higher hospital procedural volume and improved patient outcomes. ${ }^{1-8}$ On the basis of these data many payers and purchasers -most visibly an assortment of private sector businesses in the United States - have organised into the Leapfrog Group coalition to advocate for minimum volume thresholds for hospitals carrying out many complex procedures. In both the United States and Europe, efforts have been made to concentrate certain medical procedures in high volume hospitals, with hopes of improving patient outcomes at a population level. $^{8-11}$

Hospital specialisation differs from hospital volume and can be defined as the proportion of a specific hospital's admissions falling into a single disease category -for example, orthopaedics. Although hospital specialisation offers a range of theoretical benefits, ${ }^{12} 13$ empirical data are limited and most studies deal with hospital specialisation only tangentially. For example, an array of articles in both the lay press and the medical literature have highlighted "world class" hernia outcomes achieved by Shouldice Hernia Centre in Canada. ${ }^{145}$ More recently, hospital specialisation has gained favour in the United States with the development of physician owned specialty hospitals that typically focus on single diseases or procedures, such as heart disease or orthopaedic surgery. ${ }^{16-19}$ Analyses assessing outcomes in these hospitals have typically been limited by the small number of such hospitals and the fact that these analyses typically have treated hospital specialisation as a dichotomous measure (specialty hospitals, yes or no). In defining specialisation so narrowly these studies have overlooked the fact that hospital specialisation is actually a continuous measure that can be broadly applied to most hospitals. To the best of our knowledge, the relation between hospital specialisation and patient outcomes has not been investigated previously. 
To examine the relation between hospital orthopaedic specialisation and postoperative surgical outcomes we carried out a retrospective cohort study of US Medicare beneficiaries (all Americans aged 65 and older) who underwent total hip replacement or total knee replacement. We developed a measure of a hospital's orthopaedic specialisation and then compared the demographics, socioeconomic status, and prevalence of comorbid illness among patients who received total hip replacement or total knee replacement in hospitals with lower and higher degrees of orthopaedic specialisation. We then assessed the structural characteristics of less and more specialised hospitals. Lastly, we compared risk adjusted and volume adjusted outcomes of patients who underwent joint replacement surgery in hospitals with lower and higher degrees of orthopaedic specialisation. We hypothesised that hospitals with increased orthopaedic specialisation would have improved patient outcomes after adjusting for patient characteristics, hospital characteristics, and hospital procedural volume.

\section{METHODS}

We used data files from Medicare provider analysis and review part A to identify beneficiaries who underwent total hip replacement $(n=483970)$ or total knee replacement $(n=873125)$ from 2001-5. Medicare is an insurance programme operated by the US government and serves as the primary insurance for all Americans aged 65 or older. Patients were identified using the ICD-9CM (international classification of diseases, ninth revision, clinical modification) procedure codes (81.51 and 81.53 for primary and revision total hip replacement, 81.54 and 81.55 for primary and revision total knee replacement). ${ }^{5620}$ The part A files contain a range of data collected from discharge abstracts for all fee for service Medicare enrolees admitted to hospital, including patient characteristics, postal code of primary residence, ICD-9CM codes for primary and secondary diagnoses and procedures, admission source (for example, emergency department or transfer from outside hospital), admission and discharge dates, discharge disposition (for example, home, another acute care hospital, death), death occurring up to three years after discharge, each patient's unique Medicare beneficiary number allowing for identification of readmissions, and each hospital's unique six digit identification number. We obtained postal code level median household income for each patient by linking the postal code of residence in the Medicare provider analysis and review files to postal code level income data available from the 2000 US census. ${ }^{21}$ Comorbid illnesses were identified using algorithms described previously ${ }^{22}$ and updated by other researchers, ${ }^{23}$ which consider 30 specific conditions and exclude comorbidities that may represent complications of care or that are related to the primary reason for admission to hospital. Additional high risk conditions specific to joint replacement surgery (previous hip or knee replacement, acute fracture, and active joint infection) were identified using methods defined in previous studies using administrative data to assess orthopaedic outcomes, and were considered as additional comorbid conditions. ${ }^{52425}$

As is customary in studies using administrative data to assess orthopaedic outcomes, we excluded several patient populations from our primary analysis, including patients who underwent joint replacement after transfer from another acute care hospital $(n=3764)$, those with acute fractures $(n=41192)$, those who had partial hip replacements $(\mathrm{n}=465)$, and those who had received multiple joint replacements during the index admission $(n=2831)$. These patient populations are generally excluded from studies assessing orthopaedic outcomes because they are usually heterogeneous and are at especially high risk of adverse outcomes in ways that may not be well captured using administrative data. ${ }^{5617}$ We excluded patients that had missing data on race $(\mathrm{n}=5583)$ and on postal codes as this precluded us from obtaining socioeconomic measures for these patients through linkage with the US census data $(n=$ $31447)$. We calculated primary and revision total hip replacement and total knee replacement volume as well as aggregate annual joint replacement volume for each hospital by summing the number of procedures done in each hospital in the Medicare provider analysis and review data during each year. By linking the Medicare data to the 2006 American Hospital Association annual survey ${ }^{2627}$ we obtained additional hospital characteristics, including whether each hospital was a major teaching centre, whether each hospital was or was not owned by physicians, the total number of annual admissions, and the number of hospital beds. We excluded 24 hospitals ( $n=1577$ patients) that could not be linked to the survey. In total, application of all exclusion criteria resulted in the exclusion of 84014 patients $(6 \%$ of the initial sample). The sum of the listed exclusions does not equal the total reported exclusions because some patients had more than one type of missing data.

\section{Measurement of hospital orthopaedic specialisation}

We calculated the degree of each hospital's orthopaedic specialisation by building on methods developed for identification of physician owned specialty hospitals. ${ }^{16172829}$ Specifically, for each hospital we calculated the percentage of Medicare admissions classified as major diagnostic criteria 8 (diseases of the musculoskeletal system) during 2001-5; each hospital's specialisation could range from 0 (no admissions for major diagnostic criteria 8) to 100 (all admissions classified as major diagnostic criteria 8). We used graphical techniques and univariate methods to examine the distribution of orthopaedic specialisation among all US hospitals carrying out major joint replacement. We then stratified the hospitals into fourths, fifths, and 10ths containing equal numbers of hospitals based on their degree of orthopaedic specialisation, with fifths serving as the basis for our primary analyses.

\section{Statistical analysis}

Firstly, we evaluated trends in personal characteristics, socioeconomic status, and prevalence of comorbid 
illness of patients admitted to hospitals across fifths of orthopaedic specialisation (lowest fifth, least specialised; highest fifth, most specialised). We used logistic regression for dichotomous patient characteristics, such as percentage with diabetes, and linear regression for continuous variables, such as patient's age, while controlling for clustering of patients within hospitals. Secondly, we used similar statistical methods to compare the characteristics of less specialised with more specialised hospitals. Specifically we compared the annual number of Medicare admissions, annual orthopaedic (major diagnostic criteria 8) admissions, annual joint replacement volumes, number of beds, hospital ownership status, and hospital teaching status between each fifth of orthopaedic specialisation.

Thirdly, we compared rates of adverse outcomes and length of hospital stay across fifths of orthopaedic specialisation for patients treated in hospitals. In particular we examined rates of six separate adverse outcomes occurring during the index admission or within 90 days of surgery that have been used in previous studies using administrative data to assess orthopaedic outcomes, including ${ }^{56253031}$ pulmonary embolism, deep vein thrombosis, postoperative haemorrhage, deep wound infection, and death, as well as myocardial infarction during the index admission. The primary outcome was a composite representing the occurrence of one or more of these adverse outcomes. The secondary outcome of interest was death within 90 days of the index surgery.

Fourthly, we used multivariable generalised linear models with a logit link to compare the odds of both the composite outcome and mortality with hospital specialisation, from the least specialised hospitals (lowest fifth) to the most specialised hospitals (highest fifth the reference category). ${ }^{32} 33$ We used these models to compare both the unadjusted odds of adverse outcomes and the adjusted odds of adverse outcomes with hospital specialisation after accounting for the differences in patient and hospital characteristics, and hospital procedural volume. We further accounted for the clustering of patients within hospitals with models using random effects. In developing the multivariable models we specified that key covariates, including patient characteristics and procedure type (primary or revision total hip replacement or total knee replacement), be included in our models; whereas other variables such as comorbid illnesses were included in the model only if they were significantly associated with the outcome at an $\alpha \leq 0.15$. The final model for the composite outcome contained 40 variables (see web extra appendix 1). For each multivariable model we carried out a test for trend for the hospital specialisation variable $(\mathrm{P}<0.01)$. Model discrimination was evaluated using the $\mathrm{c}$ statistic (mortality 0.80 and composite 0.70 ) and calibration was assessed using the Hosmer-Lemeshow statistic. ${ }^{3435}$ All analyses were done using SAS 9.0.

\section{Sensitivity analysis}

To ensure the robustness of our findings we carried out several secondary analyses. Firstly, we repeated our analyses while including patient populations excluded in our primary analyses (for example, those admitted after hospital transfer, those with acute fractures) (see web extra appendix 2). Secondly, we repeated our analyses using alternative definitions of hospital specialisation including stratifying hospitals into fourths (see web extra appendix 4) and 10ths (see web extra appendix 5) of orthopaedic specialisation and including hospital specialisation as a continuous measure rather than a categorical one. Thirdly, we repeated our regression analyses to examine the association between fifth of hospital specialisation and each of the individual components of the composite outcome, such as deep vein thrombosis, infection, or myocardial infarction. Fourthly, we divided hospitals into low ( $<25$ total hip replacement and total knee replacement procedures annually), medium (26-100), and high (>100) volume strata and repeated our multivariable analyses, to explore whether the relation between hospital specialisation and outcomes was similar among hospitals with similar joint replacement volumes. Finally, we carried out separate analyses for patients receiving each of the four types of procedure (primary and revision total hip replacement and total knee replacement) (see web extra appendix 3).

\section{RESULTS}

The 3818 study hospitals carried out 1273081 major joint replacements from 2001-5. Patient characteristics and comorbidity varied as hospital specialisation increased (table 1). In particular, more specialised hospitals treated a lower proportion of women and African-Americans $(\mathrm{P}<0.001$ for each) and those with fewer comorbid illnesses, including diabetes and heart failure (table 1).

\section{Hospital characteristics}

The mean orthopaedic specialisation for the 3818 study hospitals was $12.4 \%$ (median 10.5\%; figure). The mean orthopaedic specialisation for hospitals in the lowest fifth was $5.5 \%$, second fifth $8.5 \%$, third fifth $10.5 \%$, fourth fifth $12.9 \%$, and highest fifth $24.5 \%$ (table 2). More specialised hospitals on average carried out significantly greater volumes of both primary and revision joint replacements $(\mathrm{P}<0.001)$. Hospitals with the greatest degree of specialisation (highest fifth) were more likely than hospitals in the other fifths to be physician owned, but even among the most specialised hospitals only $8.4 \%$ were physician owned (table 2 ).

\section{Outcomes}

As hospital orthopaedic specialisation increased, unadjusted rates of each of the five adverse outcomes decreased progressively (table 3). For example, 90 day mortality for patients who received joint replacement decreased from $1.4 \%$ in the least specialised hospitals to $0.7 \%$ in the most specialised hospitals, and rates of the composite outcome for the most specialised hospitals declined from $5.9 \%$ to $3.8 \%(\mathrm{P}<0.001$; table 3$)$.

In unadjusted regression models that accounted for clustering of patients within hospitals the odds of both 
Table 1|Demographics, socioeconomic measures, and comorbidity of Medicare patients who underwent major joint replacement from 2001-5. Values are numbers (percentages) unless stated otherwise

\begin{tabular}{|c|c|c|c|c|c|c|}
\hline \multirow[b]{2}{*}{ Characteristics } & \multicolumn{5}{|c|}{ Fifths of specialisation* } & \multirow[b]{2}{*}{$P$ value $†$} \\
\hline & First $(n=40845)$ & Second $(n=161$ 138) & Third $(n=258395)$ & Fourth $(n=360652)$ & Fifth $(n=452051)$ & \\
\hline Mean (SD) age (years) & $74.9(6.2)$ & $75.1(6.1)$ & $75.1(6.1)$ & $75.2(6.1)$ & $75.1(6.1)$ & $<0.001$ \\
\hline Women & $28172(69.0)$ & $107459(66.7)$ & $169142(65.5)$ & 231477 (64.2) & 284438 (62.9) & $<0.001$ \\
\hline \multicolumn{7}{|l|}{ Ethnic origin: } \\
\hline Non-Hispanic white & $31727(77.7)$ & $141476(87.8)$ & 236507 (91.5) & 337632 (93.6) & 430514 (95.2) & $<0.001$ \\
\hline African-American & $6529(16.0)$ & $13718(8.5)$ & $15548(6.0)$ & $14978(4.2)$ & $12068(2.7)$ & $<0.001$ \\
\hline $\begin{array}{l}\text { Median (interquartile range) } \\
\text { per capita income (\$) }\end{array}$ & $\begin{array}{c}36343 \\
\text { (29 263 to } 49083)\end{array}$ & $\begin{array}{c}42665 \\
\text { (31565 to } 50479 \text { ) }\end{array}$ & $\begin{array}{c}40352 \\
\text { (33115 to } 51581)\end{array}$ & $\begin{array}{c}41750 \\
(34231 \text { to } 53006)\end{array}$ & $\begin{array}{c}40337 \\
\text { (33973 to } 51 \text { 159) }\end{array}$ & $<0.001$ \\
\hline \multicolumn{7}{|l|}{ Comorbidity: } \\
\hline Diabetes & 7839 (19.2) & $28257(17.5)$ & $43575(16.9)$ & 55742 (15.5) & $64256(14.2)$ & $<0.001$ \\
\hline Hypertension & $26231(64.2)$ & 103321 (64.1) & $164949(63.8)$ & $223143(61.9)$ & $271153(60.0)$ & $<0.001$ \\
\hline Congestive heart failure & $2216(5.4)$ & $7825(4.9)$ & $12091(4.7)$ & $15729(4.4)$ & $17818(3.9)$ & $<0.001$ \\
\hline Chronic obstructive pulmonary disease & $5724(14.0)$ & $21255(13.2)$ & $33342(12.9)$ & $44542(12.4)$ & $51718(11.4)$ & $<0.001$ \\
\hline Obesity & $2524(6.2)$ & $9825(6.1)$ & $17090(6.6)$ & $22660(6.3)$ & $27852(6.2)$ & 0.022 \\
\hline$\geq 4$ comordid conditions & $12490(30.6)$ & 48978 (30.4) & $77580(30.0)$ & $102018(28.3)$ & $120206(26.6)$ & $<0.001$ \\
\hline
\end{tabular}

*From lowest fifth (least specialised) to highest fifth (most specialised).

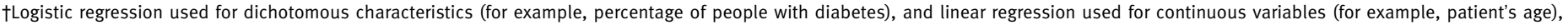
treating hospital fifths as continuous variables and controlling for clustering within hospitals.

the composite outcome and mortality declined progressively as hospital specialisation increased (highest fifth the reference category; table 4). After adjustment for patient characteristics, comorbidity, hospital characteristics, procedure type, and procedure volume, increased specialisation continued to be associated with lower odds of the composite outcome, mortality, and each of the individual components of the composite outcome (table 4). In each of our additional sensitivity analyses the results remained similar. For example, after stratifying study hospitals into low, medium, and high volume groups, the adjusted odds of the composite outcome decreased as specialisation increased among hospitals with a similar volume of orthopaedic procedures (table 5). The best outcomes were in the most specialised high volume centres (table 5).

\section{DISCUSSION}

Hospitals with a higher degree of orthopaedic specialisation had improved orthopaedic outcomes, as measured by administrative data in patients aged 65 and older. The superior results in more specialised hospitals persisted after adjusting for differences in patient and hospital characteristics and hospital orthopaedic volume. The improved outcomes we observed in more specialised hospitals were robust to an array of sensitivity analyses, including alternative measures of hospital specialisation, assessment of an assortment of diverse orthopaedic outcomes, and alternative definitions of our study population. In aggregate, these findings suggest that hospital specialisation may be an important new metric for assessing hospital performance.

\section{Limitations of the study}

Our study has several limitations. Firstly, our analysis focused on US Medicare beneficiaries aged 65 and older who had joint replacement surgery, so our results should be extrapolated with caution to other patient populations such as younger patients and those being treated outside the United States. Given the well recognised differences between the US healthcare system and the rest of the world in both the financing and delivery of care, our results require validation using data from other countries. That being said, there is no a priori reason to assume that the benefits of specialisation that we observed would not apply outside the United States. Secondly, our analysis was done using administrative data. The use of ICD-9 codes to assess clinical status is the most notable drawback in using administrative databases to measure outcomes. ICD-9 codes may not be able to capture abnormalities detected in the laboratory or on physical examination that have important prognostic value. Coding practices as well as errors in coding may differ between individual physicians and institutions. Thus our results are subject to an array of potential biases, including differences in unmeasured severity between patients treated in more and less specialised hospitals or differences in

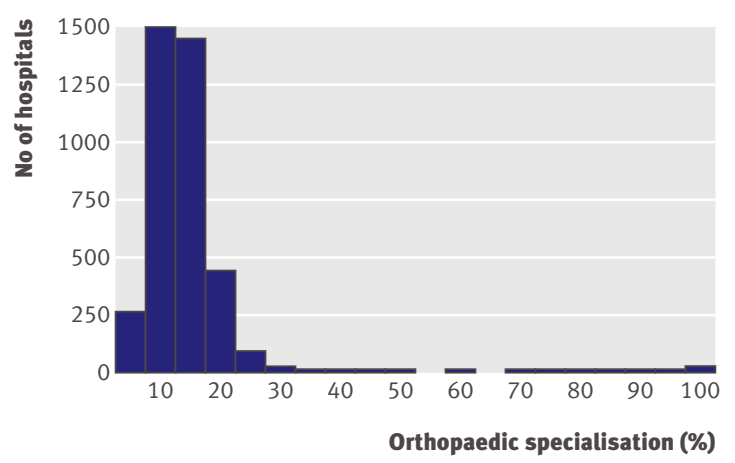

Range of orthopaedic specialisation among US hospitals carrying out major joint replacement on Medicare beneficiaries, 2001-5 
Table 2 |Characteristics of hospitals carrying out major joint replacement on Medicare beneficiaries, 2001-5. Values are medians (interquartile ranges) unless stated otherwise

\begin{tabular}{|c|c|c|c|c|c|c|}
\hline \multirow[b]{2}{*}{ Characteristics } & \multicolumn{5}{|c|}{ Fifths of specialisation* } & \multirow[b]{2}{*}{$\mathrm{P}$ value $†$} \\
\hline & First $(n=764)$ & Second $(n=763)$ & Third $(n=764)$ & Fourth $(n=763)$ & Fifth $(n=764)$ & \\
\hline Range of orthopaedic specialisation (\%) & $1.2-7.3$ & 7.3-9.5 & $9.5-11.5$ & $11.6-14.5$ & $14.5-100$ & NA \\
\hline Mean (SD) orthopaedic specialisation & $5.5(1.3)$ & $8.5(0.64)$ & $10.5(0.58)$ & $12.9(0.87)$ & $24.5(19.6)$ & $<0.001$ \\
\hline Orthopaedic specialisation & $5.8(4.8-6.6)$ & $8.5(7.9-9.1)$ & $10.5(10.0-11.1)$ & $12.9(12.1-13.6)$ & $17.2(15.6-21.4)$ & $<0.001$ \\
\hline \multicolumn{7}{|l|}{ Annual admissions: } \\
\hline Medicare & $1238(687-2286)$ & $2055(939-3956)$ & $2312(972-4642)$ & $2490(919-4652)$ & $1545(532-3371)$ & 0.002 \\
\hline Major diagnostic criteria 8 & $66(34-131)$ & $172(81-334)$ & $246(103-488)$ & $312(120-604)$ & $288(116-606)$ & $<0.001$ \\
\hline \multicolumn{7}{|l|}{ Annual No of procedures: } \\
\hline Primary hip replacements & $1.5(0.5-3.6)$ & $6.7(2.6-15.2)$ & $12.6(4.6-24.8)$ & $19.0(6.7-35.8)$ & $20.3(8.0-46.9)$ & 0.076 \\
\hline Revision hip replacements & $0(0-0.5)$ & $0.75(0.2-2.0)$ & $1.4(0.4-3.2)$ & $2.0(0.5-5.0)$ & $2.3(0.5-6.8)$ & $<0.001$ \\
\hline Primary knee replacements & $4.1(1.5-9.5)$ & $15.8(7.0-34.2)$ & $28.4(10.8-56.5)$ & $42.0(16.6-76.6)$ & $46.4(18.4-93.0)$ & $<0.001$ \\
\hline Revision knee replacements & $0(0-0.4)$ & $0.6(0-1.6)$ & $1.2(0.4-3.0)$ & $1.8(0.5-4.4)$ & $2.4(0.6-6.0)$ & $<0.001$ \\
\hline No of hospital beds & $125(67-217)$ & $159(83-262)$ & $166(78-297)$ & $158(83-294)$ & $114(49-217)$ & 0.056 \\
\hline Hospitals with physician ownership (\%) & $3(0.4)$ & $3(0.4)$ & $0(0)$ & $2(0.3)$ & $66(8.6)$ & $<0.001$ \\
\hline Teaching hospitals (\%) & $62(8.2)$ & $57(7.5)$ & $68(8.9)$ & $64(8.4)$ & $34(4.5)$ & 0.033 \\
\hline
\end{tabular}

capture of adverse outcomes across hospitals. ${ }^{31}$ Likewise, our reliance on administrative data limited our ability to assess other important measures of orthopaedic outcomes, including patient satisfaction and functional status that are not captured by administrative data. Thirdly, our study focused on the relation between orthopaedic specialisation and orthopaedic outcomes and caution should be used in generalising the relation to other types of specialisation and procedures such as paediatrics, cancer care, and cardiovascular diseases.

Finally, and perhaps most importantly, although our study suggests that greater orthopaedic specialisation is associated with improved patient outcomes, we do not examine the direction of this relation. ${ }^{36}$ It is possible that hospitals with better baseline orthopaedic performance "choose" to specialise in orthopaedics over time while avoiding other areas of care. Alternatively, it is possible that hospitals that "choose" to specialise in orthopaedics develop improved outcomes as a consequence of their specialisation. ${ }^{37}$ Another scenario is that patients who are predisposed to improved outcomes in ways that were not captured by our risk adjusted models may seek care at the more specialised hospitals. For example, wealthier or better educated patients may be expected to have better health status in both measured and unmeasured ways. If such patients choose to have surgery at more specialised hospitals, this could give the appearance of better outcomes in such hospitals when observed differences are actually due to residual confounding. We were unable to adjust for several variables that could have an impact on postoperative outcomes, including body mass index, educational attainment, and tobacco use. Likewise, although we were able to adjust for some aspects of socioeconomic status (postal code level median income) this is known to be an imperfect measure of individual patients' socioeconomic status. Our finding

Table 3 | Outcomes in Medicare beneficiaries undergoing major joint replacement, 2001-5. Values are numbers (percentages) unless stated otherwise

\begin{tabular}{|c|c|c|c|c|c|c|}
\hline \multirow[b]{2}{*}{ Outcome } & \multicolumn{5}{|c|}{ Fifths of specialisation* } & \multirow[b]{2}{*}{ Pvalue $\dagger$} \\
\hline & $\begin{array}{c}\text { First } \\
(n=40845)\end{array}$ & $\begin{array}{c}\text { Second } \\
(n=161 \text { 138) }\end{array}$ & $\begin{array}{c}\text { Third } \\
(n=258395)\end{array}$ & $\begin{array}{c}\text { Fourth } \\
(n=360652)\end{array}$ & $\begin{array}{c}\text { Fifth } \\
(n=452051)\end{array}$ & \\
\hline Mean (SD) unadjusted length of hospital stay & $4.72(4.1)$ & $4.39(2.9)$ & $4.21(2.7)$ & $4.20(2.5)$ & $4.17(2.2)$ & $<0.001$ \\
\hline 90 day mortality & $560(1.4)$ & $1868(1.2)$ & $2582(1.0)$ & $3100(0.86)$ & $3290(0.73)$ & $<0.001$ \\
\hline Postoperative infection & $1071(2.6)$ & $3174(2.0)$ & $4392(1.7)$ & $5431(1.5)$ & $5947(1.3)$ & $<0.001$ \\
\hline Postoperative haemorrhage & $1086(2.7)$ & $3251(2.0)$ & $5294(2.1)$ & $6435(1.8)$ & $7088(1.6)$ & $<0.001$ \\
\hline Deep vein thrombosis & $907(2.2)$ & 2964 (1.8) & $4674(1.8)$ & $5519(1.5)$ & $6221(1.4)$ & $<0.001$ \\
\hline Pulmonary embolism & $401(0.98)$ & $1515(0.94)$ & $2349(0.91)$ & $3024(0.84)$ & $3697(0.82)$ & $<0.001$ \\
\hline Myocardial infarction & $264(0.65)$ & $892(0.55)$ & $1338(0.52)$ & $1765(0.49)$ & $2003(0.44)$ & $<0.001$ \\
\hline 90 day composite outcome & $2399(5.9)$ & $7791(4.8)$ & $12252(4.7)$ & $14879(4.1)$ & $17015(3.8)$ & $<0.001$ \\
\hline
\end{tabular}


Table 4 | Unadjusted and adjusted odds of 90 day mortality or composite outcome and adjusted odds of individual outcomes among patients undergoing major joint replacement at progressively more specialised hospitals, with most specialised hospitals (highest fifth) as reference

\begin{tabular}{|c|c|c|c|c|c|}
\hline \multirow[b]{2}{*}{ Variables } & \multicolumn{5}{|c|}{ Fifths of specialisation* } \\
\hline & First & Second & Third & Fourth & Fifth \\
\hline \multicolumn{6}{|l|}{ Mortality: } \\
\hline Unadjusted & 1.90 (1.73 to 2.08$)$ & 1.60 (1.51 to 1.69$)$ & 1.38 (1.31 to 1.45$)$ & 1.18 (1.13 to 1.24$)$ & 1.00 \\
\hline Adjusted $\dagger$ & 1.57 (1.42 to 1.75$)$ & 1.44 (1.34 to 1.55$)$ & 1.29 (1.20 to 1.37$)$ & 1.14 (1.07 to 1.22$)$ & 1.00 \\
\hline \multicolumn{6}{|l|}{ Composite outcome: } \\
\hline Unadjusted & 1.60 (1.53 to 1.67$)$ & 1.30 (1.26 to 1.34$)$ & 1.27 (1.24 to 1.30$)$ & 1.10 (1.08 to 1.13$)$ & 1.00 \\
\hline Adjusted $†$ & 1.59 (1.48 to 1.72$)$ & 1.32 (1.24 to 1.40$)$ & 1.24 (1.17 to 1.32$)$ & 1.10 (1.04 to 1.17$)$ & 1.00 \\
\hline \multicolumn{6}{|l|}{ Individual outcomes: } \\
\hline Deep vein thrombosist & 1.76 (1.58 to 1.96$)$ & 1.46 (1.34 to 1.59$)$ & 1.32 (1.22 to 1.43$)$ & 1.16 (1.07 to 1.25$)$ & 1.00 \\
\hline Pulmonary embolism† & 1.16 (1.03 to 1.31$)$ & 1.12 (1.04 to 1.22 & 1.08 (1.00 to 1.16$)$ & 1.02 (0.95 to 1.09$)$ & 1.00 \\
\hline Haemorrhagia† & 1.65 (1.47 to 1.85$)$ & $1.3(1.19$ to 1.43$)$ & 1.29 (1.18 to 1.41$)$ & 1.14 (1.04 to 1.24$)$ & 1.00 \\
\hline Infection† & 1.98 (1.86 to 2.19$)$ & 1.52 (1.42 to 1.62$)$ & 1.28 (1.20 to 1.36$)$ & 1.14 (1.08 to 1.21$)$ & 1.00 \\
\hline Myocardial infarction $†$ & 1.34 (1.16 to 1.55$)$ & 1.17 (1.06 to 1.29$)$ & 1.09 (0.99 to 1.20$)$ & 1.05 (0.97 to 1.15$)$ & 1.00 \\
\hline
\end{tabular}

*From lowest fifth (least specialised) to highest fifth (most specialised).

†Adjusted for patient's age, sex, race, comorbid conditions (for example, diabetes, hypertension, chronic obstructive pulmonary disease, peripheral vascular disease, cerebral vascular disease, paralysis), hospital characteristics (for example, volume, teaching affiliation, bed size). See web extra appendix 1.

that the median income of the patients in the study increased along with hospital specialisation may suggest that an unmeasured aspect of socioeconomic status is acting as a residual cofounder. Thus we can not exclude that unmeasured variables, rather than hospital specialisation, are responsible for the improved postoperative patient outcomes observed in the study. We did attempt to control for this potential relation by adding variables for both patient income and area of residence into the analysis. That said, we recognise that it is impossible to eliminate completely the risk of residual confounding.

\section{Overview of previous studies}

While many studies have shown an association between higher hospital volume and improved patient outcomes, not all have found this to be the case. ${ }^{738}$ This has led investigators to question whether the volumeoutcome relation might differ for surgical and non-surgical conditions, whether the relation might be declining over time, and whether the observed advantage of high volume centres might be an artefact of incomplete adjustment of case mix. ${ }^{39}$

The relation between hospital specialisation and patient outcomes has received relatively little attention outside analyses focusing on the small number $(<150)$ of physician owned specialty hospitals currently operating in the United States. These studies have found that patients treated in physician owned specialty hospitals may have $15-20 \%$ reductions in risk adjusted adverse outcomes, with a greater improvement in outcomes among specialty orthopaedic hospitals compared with specialty cardiac hospitals. ${ }^{161719}$ Far fewer studies have looked at the more general relation between hospital specialisation and patient outcomes and all have focused exclusively on cardiac specialisation. One study grouped US hospitals into three strata of cardiac specialisation and then examined the relation between cardiac specialisation and outcomes after coronary artery bypass surgery. ${ }^{18}$ While the investigators found no improvement in outcomes among the more specialised group of hospitals, about $84 \%$ of the hospitals were classified as "low specialisation," with only $1.8 \%$ of the hospitals being classified as "high specialisation." Another study found improved outcomes for patients with ST elevation myocardial infarction treated in hospitals with a greater degree of specialisation in percutaneous coronary inter vention. ${ }^{40}$ To the best of our knowledge our analysis is the first study of the relation between hospital orthopaedic specialisation and orthopaedic outcomes in a highly representative patient population.

Measurement of hospital volume, hospital specialisation, and outcomes

In interpreting our results it is important to recognise that although volume and specialisation both provide quantitative measure of a hospital's activities, they represent fundamentally distinct measures of hospital care. Hospital volume is typically calculated as the number of specific procedures (for example, bypass surgery) carried out or patients admitted with a specific diagnosis, such as pneumonia, during a circumscribed period. Alternatively, hospital specialisation is measured as the proportion of a hospital's total admissions during a circumscribed period that have a specific procedure (for example, hip replacement surgery) or fall into a single disease category, such as orthopaedics. While hospital volume appears to be closely correlated with hospital size (total number of beds), it does not seem that hospital specialisation is as closely correlated with hospital size. In our study, hospital specialisation was not related to the number of beds and no clear trend was observed between total Medicare 
Table $5 \mid$ Adjusted odds* (95\% confidence intervals) of 90 day composite outcome among patients undergoing major joint replacement at progressively more specialised hospitals, with highest volume most specialised hospital (>100 cases, top fifth) as reference

\begin{tabular}{|c|c|c|c|c|c|}
\hline \multirow[b]{2}{*}{ Composite } & \multicolumn{5}{|c|}{ Fifths of specialisation $†$} \\
\hline & First & Second & Third & Fourth & Fifth \\
\hline Low volume ( 225 cases) & 1.89 (1.72 to 2.07$)$ & $1.56(1.40$ to 1.74$)$ & $1.60(1.41$ to 1.83$)$ & $1.60(1.37$ to 1.87$)$ & $1.46(1.21$ to 1.78$)$ \\
\hline High volume ( $>100$ cases) & 1.47 (1.06 to 2.04$)$ & 1.27 (1.15 to 1.39$)$ & 1.22 (1.14 to 1.32$)$ & $1.10(1.03$ to 1.18$)$ & 1.00 \\
\hline
\end{tabular}

*Adjusted for patient's age, sex, race, comorbid conditions (for example, diabetes, hypertension, chronic obstructive pulmonary disease, peripheral vascular disease, cerebral vascular disease, paralysis, and hospital characteristics (for example, volume, teaching affiliation, bed size). †From lowest fifth (least specialised) to highest fifth (most specialised).

admissions and degree of specialisation. Intuitively, a large hospital is more likely to have high volumes for all diagnoses and procedures, but being high volume for multiple diagnoses would tend to reduce hospital specialisation. Conversely, a small or medium sized hospital as measured by the number of beds could be highly specialised by focusing on a single disease or disease category.

\section{Mechanisms of action for volume and specialisation leading to improved outcomes}

In considering our results it is also important to reflect on how volume and specialisation might affect patient outcomes. While early studies focused on the association between higher hospital volume and improved patient outcomes, more recent studies have shown that the association between physician volume and patient outcomes is as strong if not stronger than the hospital volume effect. ${ }^{4142}$ Given the limited data assessing the relation between hospital specialisation and patient outcomes, further study is required to examine the robustness of our findings for other medical diagnoses and study settings.

Despite an abundance of studies using administrative data sources to document the association between higher hospital or provider volume or specialisation and improved patient outcomes, more detailed analyses showing potential mechanisms of action are

\section{WHAT IS ALREADY KNOWN ON THIS TOPIC}

Numerous studies have shown an association between higher hospital procedural volume and improved patient outcomes

Recent analyses also suggest improved outcomes for patients treated in a limited number of US hospitals focusing on orthopaedic care, but it is uncertain whether such specialisation is more broadly associated with improved patient outcomes

\section{WHAT THIS STUDY ADDS}

Even small increases in orthopaedic specialisation are associated with significant improvements in patient outcomes after adjusting for both patient characteristics and hospital procedural volume

The possibility that unmeasured aspects of socioeconomic status or other confounding factors, rather than hospital specialisation, are responsible for the improved outcomes in specialty hospitals cannot be excluded

Hospital specialisation may capture different components of hospital quality of care than hospital volume limited. We suspect that the association may reflect what is commonly described as the learning curve or "practise makes perfect." ${ }^{444}$ Alternatively, we would hypothesise that hospital volume and specialisation may reflect different aspects of the experience of the entire clinical care team with a specific population of patients. However, empirical studies assessing the factors underlying the associations between volume, specialisation, and outcomes are in their infancy. ${ }^{1245}$

\section{Conclusions and implications}

Our findings suggest that increased hospital orthopaedic specialisation is associated with improved patient outcomes. Our results require rapid and rigorous replication using data on patients with other diseases, such as cancer or cardiovascular disease, and data from other countries. If our findings were validated, these results would have significant implications for where patients might select to receive their care and the organisation of that care. Until such studies are completed, our work suggests that older patients requiring joint replacement surgery in the United States, and their physicians, should consider both the specialisation and the volume of available hospital choices.

Contributors: All authors conceived and designed the study, analysed and interpreted the data, drafted the article or revised it critically for important intellectual content, and gave final approval of the version to be published. TPH is guarantor

Funding: MSV-S is a research scientist in the Center for Research in the Implementation of Innovative Strategies in Practice (CRIISP) at the lowa City VA Medical Center, which is funded through the Department of Veterans Affairs, Veterans Health Administration, Health Services Research and Development Service. PC is supported by a K23 career development award (RR01997201) from the National Center for Research Resources, National Institutes of Health; the Robert Wood Johnson faculty scholars programme; and R01 HL085347-01A1 from the National Heart, Lung, and Blood Institute, National Institutes of Health. The views expressed in this article are those of the authors and do not necessarily represent those of the Department of Veterans Affairs. Competing interests: All authors have completed the unified competing interest form at www.icmje.org/coi_disclosure.pdf (available on reques from the corresponding author) and declare (1) no financial support for the submitted work from anyone other than their employer; (2) no financial relationships with commercial entities that might have an interest in the submitted work; (3) no spouses, partners, or children with relationships with commercial entities that might have an interest in the submitted work; and (4) no non-financial interests that may be relevant to the submitted work.

Ethical approval: This study was approved by the University of lowa and lowa City Veterans Affairs Medical Center institutional review boards. Data sharing: Results for additional sensitivity analyses are available from the corresponding author at tyson-hagen@uiowa.edu. 
1 Hannan EL, O’Donnell JF, Kilburn H Jr, Bernard HR, Yazici A. Investigation of the relationship between volume and mortality for surgical procedures performed in New York State hospitals. JAMA 1989;262:503-10

2 Begg CB, Cramer LD, Hoskins WJ, Brennan MF. Impact of hospital volume on operative mortality for major cancer surgery. JAMA 1998;280:1747-51.

3 Hannan EL, Radzyner M, Rubin D, Dougherty J, Brennan MF. The influence of hospital and surgeon volume on in-hospital mortality fo colectomy, gastrectomy, and lung lobectomy in patients with cancer. Surgery 2002;131:6-15.

4 Birkmeyer JD, Stukel TA, Siewers AE, Goodney PP, Wennberg DE, Lucas FL. Surgeon volume and operative mortality in the United States. N Engl J Med 2003;349:2117-27.

5 Katz JN, Losina E, Barrett J, Phillips CB, Mahomed NN, Lew RA, et al. Association between hospital and surgeon procedure volume and outcomes of total hip replacement in the United States medicare population. J Bone Joint Surg Am 2001;83-A:1622-9.

6 Katz JN, Barrett J, Mahomed NN, Baron JA, Wright RJ, Losina E. Association between hospital and surgeon procedure volume and the outcomes of total knee replacement. J Bone Joint Surg Am 2004;86-A:1909-16.

7 Halm EA, Lee C, Chassin MR. Is volume related to outcome in health care? A systematic review and methodologic critique of the literature. Ann Intern Med 2002;137:511-20.

8 Judge A, Chard J, Learmonth I, Dieppe P. The effects of surgical volumes and training centre status on outcomes following total joint replacement: analysis of the Hospital Episode Statistics for England. J Public Health (Oxf) 2006;28:116-24.

9 Dudley RA, Johansen KL, Brand R, Rennie DJ, Milstein A. Selective referral to high-volume hospitals: estimating potentially avoidable deaths. JAMA 2000;283:1159-66.

10 The Leapfrog Group. Purchasing principles. 2009. www. leapfroggroup.org/for_members/purchasing_principles.

11 Topal B, Van de Sande S, Fieuws S, Penninckx F. Effect of centralization of pancreaticoduodenectomy on nationwide hospital mortality and length of stay. Br / Surg 2007;94:1377-81.

12 Sexton JB, Makary MA, Tersigni AR, Pryor D, Hendrich A, Thomas EJ, et al. Teamwork in the operating room: frontline perspectives among hospitals and operating room personnel. Anesthesiology 2006;105:877-84

13 Pronovost PJ, Berenholtz SM, Goeschel C, Thom I, Watson SR, Holzmueller CG, et al. Improving patient safety in intensive care units in Michigan. J Crit Care 2008;23:207-21.

14 Devlin HB, Gillen PH, Waxman BP, MacNay RA. Short stay surgery fo inguinal hernia: experience of the Shouldice operation, 1970-1982. Br J Surg 1986;73:123-4.

15 Gawande A. Complications: a surgeon's notes on an imperfect science. Metropolitan Books, 2002.

16 Cram P, Rosenthal GE, Vaughan-Sarrazin MS. Cardiac revascularization in specialty and general hospitals. $N$ Engl J Med 2005;352:1454-62.

17 Cram P, Vaughan-Sarrazin MS, Wolf B, Katz IN, Rosenthal GE. A comparison of total hip and knee replacement in specialty and general hospitals. J Bone Joint Surg Am 2007;89:1675-84.

18 Hwang CW, Anderson GF, Diener-West M, Powe NR. Comorbidity and outcomes of coronary artery bypass graft surgery at cardiac specialty hospitals versus general hospitals. Med Care 2007;45:720-8.

19 Katz JN, Bierbaum BE, Losina E. Case mix and outcomes of total knee replacement in orthopaedic specialty hospitals. Med Care 2008;46:476-80

20 Mitchell JB, Bubolz T, Paul JE, Pashos CL, Escarce JJ, Muhlbaier LH, et al. Using medicare claims for outcomes research. Med Care 1994;(suppl 7):J38-51S.

21 US Census Bureau. United States census 2000. 2009. www.census. gov/main/www/cen2000.html.

22 Elixhauser A, Steiner C, Harris DR, Coffey RM. Comorbidity measures for use with administrative data. Med Care 1998;36:8-27.

23 Quan H, Sundararajan V, Halfon P, Fong A, Burnand B, Luthi JC, et al. Coding algorithms for defining comorbidities in ICD-9-CM and ICD-10 administrative data. Med Care 2005;43:1130-9.

24 Katz JN, Losina E, Barrett J, Phillips CB, Mahomed NN, Lew RA, et al. Association between hospital and surgeon procedure volume and outcomes of total hip replacement in the United States medicare population: appendix. J Bone Joint Surg Am 2001;83-A:1622-9.

25 Agency for Healthcare Research and Quality. Patient safety indicator download. 2007.www.qualityindicators.ahrq.gov/psi_download. htm.

26 Rosenthal GE, Harper DL, Quinn LM, Cooper GS. Severity-adjusted mortality and length of stay in teaching and nonteaching hospitals. Results of a regional study. JAMA 1997;278:485-90.

27 American Hospital Association. Health care statistics and market research: AHA data. 2009. www.ahadata.com.

28 United States General Accounting Office. Specialty hospitals: information on national market share, physician ownership, and patients served. 2003. www.gao.gov/new.items/d03683r.pdf.

29 Medicare Payment Advisory Commission. Report to congress: physician-owned specialty hospitals. 2005. www.medpac.gov/ documents/Mar05_SpecHospitals.pdf.

30 Norton EC, Garfinkel SA, McQuay LJ, Heck DA, Wright JG, Dittus R, et al. The effect of hospital volume on the in-hospital complication rate in knee replacement patients. Health Serv Res 1998;33:1191-210.

31 Phillips CB, Barrett JA, Losina E, Mahomed NN, Lingard EA Guadagnoli E, et al. Incidence rates of dislocation, pulmonary embolism, and deep infection during the first six months after elective total hip replacement. / Bone loint Surg Am 2003;85-A:20-6.

32 Liang K, Zeger SL. Longitudinal data analysis using generalized linear models. Biometrika 1986;73:13-22.

33 White $\mathrm{H}$. A heteroskedasticity-consistent covariance matrix estimato and a direct test for heteroskedasticity. Econometrica 1980;48:817-30.

34 Lemeshow S, Hosmer DW Jr. A review of goodness of fit statistics for use in the development of logistic regression models. Am J Epidemio 1982;115:92-106.

35 Ash AS, Schwartz M. Evaluating the performance of risk-adjustment methods: dichotomous outcomes. In: lezzoni U, ed. Risk adjustment for measuring healthcare outcomes. 2nd ed. Health Administration Press, 1997.

36 Barker D, Rosenthal GE, Cram P. Simultaneous relationships between procedure volume and mortality: do they bias studies of mortality at specialty hospitals? J Health Econ 2009; (in press).

37 Luft HS, Hunt SS, Maerki SC. The volume-outcome relationship: practice-makes-perfect or selective-referral patterns? Health Serv Res 1987;22:157-82.

38 Peterson ED, Coombs LP, DeLong ER, Haan CK, Ferguson TB. Procedural volume as a marker of quality for CABG surgery. JAMA 2004;291:195-201.

39 Sowden AJ, Deeks JJ, Sheldon TA. Volume and outcome in coronary artery bypass graft surgery: true association or artefact? BMJ 1995;311:151-5.

40 Nallamothu BK, Wang Y, Magid DJ, McNamara RL, Herrin J, Bradley EH, et al. Relation between hospital specialisation with primary percutaneous coronary intervention and clinical outcomes in ST-segment elevation myocardial infarction: National Registry of Myocardial Infarction-4 analysis. Circulation 2006;113:222-9.

41 McGrath PD, Wennberg DE, Dickens JD Jr, Siewers AE, Lucas FL, Malenka DJ, et al. Relation between operator and hospital volume and outcomes following percutaneous coronary interventions in the era of the coronary stent. JAMA 2000;284:3139-44.

42 Srinivas VS, Hailpern SM, Koss E, Monrad ES, Alderman MH. Effect of physician volume on the relationship between hospital volume and mortality during primary angioplasty. J Am Coll Cardiol 2009;53:574-9.

43 Luft HS. The relation between surgical volume and mortality: an exploration of causal factors and alternative models. Med Care 1980;18:940-59.

44 Luft HS, Garnick DW, Mark DH, McPhee SJ. Hospital volume, physician volume, and patient outcomes. Health Administration Press Perspectives, 1990.

45 Pronovost PJ, Sexton JB, Pham JC, Goeschel CA, Winters BD, Miller MR. Measurement of quality and assurance of safety in the critically ill. Clin Chest Med 2009;30:x,169,79.

Accepted: 30 October 2009 